\title{
Achieving a safe culture: theory and practice
}

\author{
JAMES REASON
}

Department of Psychology, University of Manchester, Manchester M13 9PL, UK

Keywords: Safety culture; Accidents; Organizationalfactors; Human error.

This paper discusses four topics relating to safety culture, three theoretical and one practical. The first considers why it is that an unsafe culture is more likely to be involved in the causation of organizational rather than individual accidents. It is the pervasive nature of culture that makes it uniquely suitable for creating and sustaining the co-linear gaps in defences-in-depth through which an accident trajectory has to pass. The second topic relates to pathological adaptations, and discusses two examples: the Royal Navy of the mid-nineteenth century and the Chernobyl reactor complex. The third issue deals with recurrent accident patterns and considers the role of cultural drivers in creating typical accidents. The final topic is concerned with the practical question of whether a safety culture can be engineered. It is argued that a safe culture is an informed culture and this, in turn, depends upon creating an effective reporting culture that is underpinned by ajust culture in which the line between acceptable and unacceptable behaviour is clearly drawn and understood.

\section{Introduction}

Although there is no universally accepted definition of safety culture, there can be little doubt that it is a concept whose time has come. Since the beginning of 1997, there have been well-attended meetings and workshops devoted exclusively to this topic, and the interest extends across many work domains. For example, the US National Transportation Safety Board's (NTSB) symposium on 'Corporate Culture and Transportation Safety' in April 1997 attracted some 550 delegates from all of its constituencies: aviation, railroads, highways, the marine world, pipelines and the safety of hazardous materials. The symposium was convened because the NTSB's accident investigators were increasingly conscious of the crucial role played by cultural factors in creating bad events (see, for example, NTSB/AAR 1994, 1997, NTSB/RAR 1996).

The high level of concern with organizational culture in the world of hazardous technologies poses both a challenge and an opportunity for those academics involved in the safety-related sciences. We need to develop a clearer theoretical understanding of these organizational issues to create a principled basis for more effective culture-enhancing practices. To this end, the paper presents arguments dealing with four culture-relatedissues, three largely theoretical and one with more directly practical applications.

First, are modern, high-tech, well-defended technologies — such as nuclear power plants, chemical process plants and commercial aviation - more vulnerable to the effects of a poor safety culture than traditional industries involving close encounters between people and hazards - as in mining, construction, the oil and gas industry, the railway infrastructure and road transport?

Second, an organizational culture does not spring up ready-made. Organizations, like organisms, adapt. Safety cultures evolve gradually in response to local conditions, past events, the character of the leadership and the mood of the workforce. How can this 
adaptation go wrong? Why do certain organizations come to value either the wrong kind of excellence, or pursue goals that carry serious safety penalties?

Third, in almost every kind of hazardous work, it is possible to recognize typical accident patterns. That different people are involved in these events clearly implicates causal factors relating to the workplace and the system at large. Local traps, involving error-provoking tasks and work conditions, have the power to lure people into repeated sequences of unsafe acts. But is this sufficient to explain such recurrences? These behavioural sequences do not occur invariably. To what extent do cultural influences act as drivers for these unhappy repetitions? Situations may pull, but do cultural influences push as well?

Finally, a practical question: can a safer culture be engineered? Or, more specifically, can we socially engineer the necessary ingredients of an effective safety culture? The paper concludes by reviewing what is known about creating a reporting culture and a just culture, two of the most important aspects of safety culture.

\section{Safety culture}

Uttal's (1983) definition of safety culture captures most of its essentials: 'Shared values (what is important) and beliefs (how things work) that interact with an organization's structures and control systems to produce behavioural norms (the way we do things around here)' The literature (Bate 1992, Thompson et al. 1996) suggests at least two ways of treating safety culture: as something an organization is (the beliefs, attitudes and values of its members regarding the pursuit of safety), and as something that an organization has (the structures practices, controls and policies designed to enhance safety). Both are essential for achieving an effective safety culture. However, as shall be argued, the latter is easier to manipulate than the former (Hofstede 1994). It is hard to change the attitudes and beliefs of adults by direct methods of persuasion. But acting and doing, shaped by organizational controls, can lead to thinking and believing.

An ideal safety culture is the 'engine' that drives the system towards the goal of sustaining the maximum resistance towards its operational hazards, regardless of the leadership's personality or current commercial concerns. Such an ideal is hard to achieve in the real world, but it is nonetheless a goal worth striving for. The power of this engine relies heavily on a continuing respect for the many entities that can penetrate, disable or bypass the system's safeguards. In short, it means not forgetting to be afraid. This is no easy task in industries with few accidents. Weick (1991) has described safety as a dynamic non-exent. Non-events, by their nature, tend to be taken for granted particularly in the face of continuous and compelling productive demands. As he pointed out, safety is invisible in the sense that safe outcomes do not deviate from the expected, and so there is nothing to capture the attention. If people see nothing they presume that nothing is happening and that nothing will continue to happen if they continue to act as before But this is misleading because it takes a number of dynamic inputs to create stable outcomes.

In the absence of frequent bad events, the best way to induce and then sustain a state of intelligent and respectful wariness is to gather the right kinds of data. This means creating a safety information system that collects, analyses and disseminates information from incidents and near misses, as well as from regular proactive checks on the system's vital signs. All of these activities can be said to make up an informed culture- one in which those who manage and operate the system have current knowledge about the human, technical, organizational and environmental factors that determine the safety of the system as a whole. In most important respects an informed culture is a safety culture. 


\section{Are well-defended technologies more vulnerable to an unsafe culture?}

The argument presented here hinges on making a distinction between two kinds of accidents: individual and organizational. The principal differences between them are summarized in figure 1. Individual accidents are ones in which a specific person or group is often both the agent and the victim. The damage to the people concerned may be great, but its spread is limited. Organizational accidents happen to systems or subsystems. They have multiple causes involving many people operating at different levels within their respective companies. Though extremely rare within any one domain, organizational accidents can have devastating effects on uninvolved populations, assets and the environment. Whereas the nature (though not necessarily the frequency) of individual accidents has remained relatively unchanged over the years, organizational accidents are a product of technological innovations that have radically altered the relationship between systems and their human elements.

Perhaps the most critical distinction between individual and organizational accidents lies in the quantity, quality and variety of the defences, barriers and safeguards that protect people and assets from the local operational hazards. Individual accidents occur in circumstances where the hazards are close to people and the defences are limited or nonexistent. Organizational accidents, on the other hand, happen to complex systems that have defences-in-depth - that is, protective measures possessing a great deal of diversity and redundancy. In nuclear power plants, modern commercial aircraft and other contemporary high-tech systems, there is invariably a mixture of 'hard' and 'soft' defences. The former include engineered safety features - such as automatic controls warning systems and shutdowns-together with various physical barriers and containments, while the latter comprise a combination of paper and people-rules and procedures training drills, administrative controls and most particularly front-line operators such as pilots and control room personnel. The result of these many layers of defence is to make these systems largely proof against single failures, either human or technical. For an accident to occur in such a system, it requires the unlikely combination of several different factors to penetrate the many protective layers and to allow hazards to come into damaging contact with plant, personnel and the environment.

One way of representing the aetiology of an organizational accident is by the 'Swiss cheese' model shown in figure 2 . Here, the defences, portrayed as cheese slices, are shown as intervening between the local hazards and potential losses. Each slice of cheese represents one layer of defence. In an ideal world, all of these layers would be intact. In reality, however, each layer has holes or gaps. These gaps are created by active failures - the errors and violations of those at the human-system interface and by latent conditions arising

\begin{tabular}{|c|c|}
\hline $\begin{array}{c}\text { Individual } \\
\text { accidents }\end{array}$ & $\begin{array}{c}\text { Organizational } \\
\text { accidents }\end{array}$ \\
\hline Frequent & Rare \\
Limited consequences & Widespread consequences \\
Few or no defences & Many defences \\
Limited causes & Multiple causes \\
Slips, trips and lapses & Product of new technology \\
Short 'history' & Long 'history' \\
\hline
\end{tabular}

Figure 1. Distinguishing the characteristics of individual and organizational accidents. 


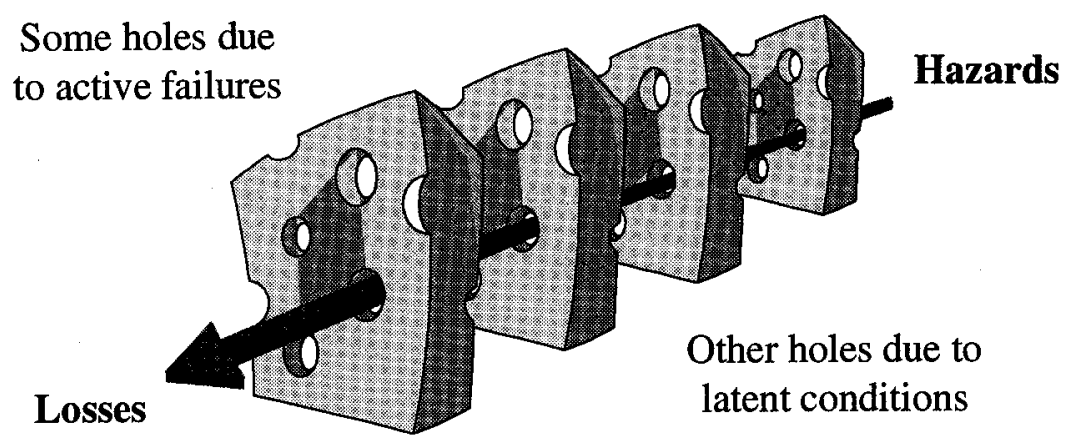

Figure 2. The 'Swiss cheese' model of defences-in-depth.

from the failure of designers, builders, managers and maintainers to anticipate all possible scenarios (see Reason 1997 for a more detailed discussion). The holes due to active failures are likely to be relatively short-lived, while those arising from latent conditions may lie dormant for many years until they are revealed by regulators internal audits or by incidents and accidents. It is also important to recognize that, unlike the holes in Swiss cheese slices, these defensive gaps are not static, especially those due to active failures. They are in continuous flux, moving around and opening and shutting according to local circumstances. This metaphor also makes it clear why organizational accidents are rare events. For such a disaster to occur, it requires a lining up of the holes to permit a brief trajectory of accident opportunity.

So why are such high-tech systems especially susceptible to the influence of safety culture? To answer this, we need to consider some of the characteristics of complex, welldefended systems.

Defences-in-depth are a mixed blessing. While they greatly reduce the likelihood of a bad accident, they also render the system as a whole more opaque to the people who manage and operate it (Rasmussen 1993). The human controllers of such systems have become remote from the processes they manipulate and, in many cases, from the hazards that potentially endanger their operations. Both this distancing effect and the rarity of bad events make it very easy not be afraid, as was evident at the Chernobyl nuclear power station (see below). Contrast this with a traditional 'close encounter' industry such as mining or construction. The working conditions may be brutal, but the dangers are very exident Even where a poor safety culture has led to the provision of inadequate tools, equipment and protectixe measures, most workers will be wary of the all too apparent local hazards. Of course, this self-protecting vigilance will lapse once in a while and accidents will happen, but the dangers are unlikely to be disregarded for very long.

The complexity and tight-coupling of complex, high-tech systems not only makes them opaque to the operators, but also they make it almost impossible for any one individual to understand such a system in its entirety (Perrow 1984). This can lead to the insidious accumulation of latent conditions that weaken the defences. If no one person can comprehend the existence of all of these holes, then no one person can be responsible for them. Some gaps will always escape attention and correction. But this would be the case even in a system with an excellent safety culture. The crucial cultural difference, it is believed, lies in what an organization does about the defensive weaknesses it actually knows about. 
Because of their diversity and redundancy, the elements of a multilayered defensive system will be widely distributed throughout the organization. As such, they are only collectively vulnerable to something that is equally widespread. The most likely candidate is safety culture. The one universally accepted feature of culture is that its influence extends to all parts of an organization. Only culture can affect all the 'cheese slices' and their associated holes.

There are at least three ways in which a less-than-adequate safety culture can adversely undermine a system's protection, and all of these influences stem, directly or indirectly, from a failure to understand and fear the full range of operational hazards. First, a poor safety culture is likely to increase the number of defensive weaknesses due to active failures. Front-line errors are more likely in organizations that are insufficiently concerned about the working conditions known to promote the slips, lapses and mistakes of both teams and individuals. These include such factors as inadequate training, poor communication, bad procedures and problems with the design of the man-machine interface. But, perhaps even more potently, a poor safety culture will encourage an atmosphere of non-compliance to safe operating practices. Violations are likely to be most common in organizations where the unspoken attitudes and beliefs mean that production and commercial goals are seen to outweigh those relating to safety. Second, an inability to appreciate the full extent of the operational dangers can lead to the creation of more longer-lasting holes in the defences. These may arise as latent conditions during maintenance, testing and calibration, or through the provision of inadequate equipment, or by downgrading the importance of training in handling emergencies.

Perhaps the most insidious and far-reaching effects of a poor safety culture, however, will be evident in an unwillingness to deal proactively with known deficiencies in the defencesin-depth. In short, defensive gaps will be worked around and allowed to persist. The history of organizational accidents is rich with examples of management neglecting or postponing the elimination of previously identified defensive weaknesses. These problems are neatly summed up in Perin's (1992) phrase: the case of the unrocked boat. She used it specifically to describe the gradual erosion of safeguards in the largely event-free years prior to the Clapham Junction railway disaster, but it applies equally well to a wide range of organizational accidents: the Piper Alpha oil platform explosion, the Challenger space shuttle disaster, the sinking of the Herald of Free Enterprise, the King's Cross Underground fire, the collapse of Barings Bank, and so on. Just prior to the collapse of Barings, for example, the London management noticed that tens of millions of pounds remained unaccounted for in the dealings of their Singapore trading office. The Group Treasurer was later to say that there was no excuse for not making balancing the books the highest priority. 'But there was always something else more pressing' (Fay 1996). This confession captures the essence of a culture-induced organizational accident. It says: "We were not sufficiently alarmed to do anything about it'.

The reasons why well-defended technological systems are especially vulnerable to cultural deficiencies can best be summarized by reference to figure 2 . An accident trajectory can only penetrate the various holes and gaps when they line up to create a path of opportunity. Such co-linearities are rare because there are many defensive layers and the holes are in continuous motion. But culture has pervasive effects that can not only open gaps

and weaknesses but also-and most importantly-it can allow them to remain uncorrected. In a well-defended system only cultural influences are sufficiently widespread to increase substantially the probability of lining up a penetrable series of defensive weaknesses. 


\section{Dangerous adaptations}

Schein (1985) proposed that culture is 'a pattern of basic assumptions invented, discovered or developed by a group as it learns to cope with its problems of external adaptation and internal integration'. But this external adaptation and internal integration can be directed to the achievement of goals that are directly contrary to the pursuit of safety, as is shown by the two cases presented below.

\subsection{The Royal Navy in the mid-nineteenth century}

From a maritime safety perspective, few activities seem more bizarre than polishing the watertight doors aboard a warship until they are no longer watertight. But this is precisely what was required of British sailors between the early $1860 \mathrm{~s}$ and the late $1880 \mathrm{~s}$. To understand how this came about, we need to examine the cultural driving forces within the Royal Navy of that period.

During the latter half of the nineteenth century, Britain was not at war with any major power. Deterrence through display became the Royal Navy's primary function in these mid-Victorian years. At the same time, it was undergoing major technological changes. Steam was replacing sail, iron was replacing the traditional oak-after three centuries in which warships had remained more or less unchanged in their basic structure and means of propulsion. The problem facing the officers of Victorian warships was to find work for under-employed hands now no longer required to rig, furl and mend sails.

Their solution was to create the cult of 'brightwork' in which ships xied with one another to produce the shiniest surfaces and the glossiest paint work. Battleship and cruiser crews spent countless hours burnishing the guns. Massive armoured watertight doors were lifted from their hinges and filed and rubbed until they gleamed-and soon became no longer watertight (Massie 1992). A ship's commander was judged not by the rate and accuracy of his gunnery but by the extent to which his ship sparkled. Ships' captains would spend large sums from their own pockets on paint and polishing materials. It was the principal road to promotion. This peacetime 'display culture' not only undermined the Royal Navy's fighting ability, it also created gleaming death traps-as in the unhappy case of HMS Camperdown, among others.

\subsection{The Chernobyl nuclear reactor complex}

We see echoes of this insouciant naval culture in the organizational climate that prevailed among those overseeing, managing and operating the Chernobyl nuclear power station at the time of its catastrophic explosion in 1986. Two cultural influences played a large part in creating this disaster, one relating to the Soviet nuclear power generation system as a whole, and the other rooted in the attitudes and beliefs of the Chernobyl staff.

The idea of nuclear power plants frightens many people, regardless of their nationality. Each country accommodates to this public relations problem in different ways. In the Soviet Union, the solution was simple: persuade the citizens that nuclear power generation was the ultimate in genuine safety, ecological cleanliness and reliability. To this end, no information was released regarding nuclear incidents or accidents, even to those in the industry who had a need to know. Medvedev, a leading Soviet nuclear engineer, explained why the Moscow-based Nuclear Safety Committee did not act to halt the electrical generation experiment, planned for 25 April, at the Number 4 reactor, although they had received notification of the plant's intentions in January. 
It was almost as if they had conspired not to intervene. Why? The fact is that there was a conspiracy of silence. Mishaps were never publicized; and as nobody knew about them, nobody could learn from them. For 35 years people did not notify each other about accidents at nuclear power stations, and nobody applied the experience of such accidents to their work. It was as if no accidents had taken place at all: everything was safe and reliable (Medvedev 1991 : 39).

Ironically, the experiment that triggered the Chernobyl tragedy was aimed at improving reactor safety. In the event of an off-site power failure, all machinery would stop, including the pumps feeding cooling water through the reactor core. Back-ups existed in the form of diesel generators, but these would require some minutes to provide the necessary power. The experiment was concerned with evaluating a stopgap measure that would use the kinetic energy of the free-spinning turbine to generate electricity. Such a test had been proposed to numerous nuclear power stations, but they had declined because of the risks involved-it would entail bypassing the reactor's safety systems. But the Chernobyl management had accepted the challenge. Why?

Tests of this device had been carried out previously at Chernobyl but had failed to produce a sustained electrical current. These tests had been conducted with the safety systems switched on and the reactor in a stable, controlled state. A different plan was proposed for 25 April 1986. On this occasion, they would exploit a scheduled maintenance shutdown to carry out the experiment while the reactor was at $25 \%$ full power prior to shutdown. They would also use a special device to regulate the generator's magnetic field and thereby-they believed-overcome the earlier problems. The programme also stipulated that the emergency core cooling system would be switched off. The Chernobyl management had high hopes that these measures would demonstrate the feasibility of the device, and there was much kudos to be had from completing a successful test. This dubious procedure was not seen as dangerous. As one plant manager told Valeri Legasov, the principal accident investigator, a nuclear power plant is, after all, only a big samovar (Legasov 1988).

The final ingredient in this calamitous cultural mix was provided by the operators. They too showed a cheerful unconcern for the risks. This blind confidence had a number of origins. In the first place, they were prize winners, having recently won an award for delivering the most kilowatts to the grid. Second, their status in Soviet society was very high, something approaching that of cosmonauts. Third, they had a 'can do' attitude. Even though the test required the reactor to be in an unfamiliar and unstable configuration, they were entirely sanguine about their ability to handle it. It cannot be said that they had forgotten to be afraid. The reality was worse: they had never learned to be afraid. The result was a tragic combination of misplaced arrogance and deadly ignorance.

This ignorance of nuclear physics became apparent during the course of the night's events. An initial operator error caused the reactor to drop to a dangerously low power level. Although this level created the serious risk (and later the reality) of a positive reactivity coefficient- essentially a runaway reactor, a singular feature of the RBMK design at low power - they persisted with the test. In the half an hour prior to the explosions, the operators disabled one safety system after another in the hope of completing the test, a prospect that seemed just within their grasp. This created yawning gaps in the system's defences-in-depth. Only in the last minute did they recognize the danger and attempt to scram the reactor by inserting the absorber rods By then, however, it was too late. The rods had buckled and the explosions were inevitable. 


\section{The cultural contribution to recurrent accidents}

Far from being entirely random, accidents have a way of falling into recurrent patterns. They are shaped in large part by the local operational circumstances. This is illustrated in the following examples.

Controlled flight into terrain (CFIT) occurs when the flight crew loses situational awareness in proximity to the ground. CFIT accidents account for $\sim 74 \%$ of fatal accidents world-wide in commercial aviation. A recent study by the Flight Safety Foundation (BASI 1995) discovered the following recurrent features:

(1) More than half of all CFIT accidents occur during step-down instrument approaches involving intermittent descents at relatively steep angles, or during approaches at abnormally shallow angles-less than one degree.

(2) About half of all CFIT accidents involve freight, charter or positioning flights.

(3) About half of all CFIT accidents involve $<3 \%$ of the world's total fleet. This $3 \%$ is not equipped with ground proximity warning systems (GPWS). It should also be noted that $<30 \%$ of the corporate and business fleet is equipped with GPWS.

(4) Inadequate charts together with significant differences between government and commercially produced charts were regarded as a significant causal factor in many CFIT accidents,

Surveys carried out by the Institute of Nuclear Power Operations in the US $(1984,1985)$ and the Centre for Research in the Electrical Power Industries in Japan (K. Takano, personal communication 1996) revealed that something $>70 \%$ of all human factors problems in nuclear power plants were maintenance-related. Of these, the majority involved the omission of necessary steps during installation or re-assembly. Similar recurrent patterns of error were also observed in aircraft maintenance (Reason 1995). In an analysis of critical incident reports from experienced aircraft maintainers. Hobbs (1997) also found omissions to be the single largest category of error. The most common local factors leading to these and other crrors were inadequate tools and equipment (e.g broken stands and faulty electrical devices), perceived pressure or haste, and environmental conditions such as bad weather, darkness and slippery work surfaces. In a study of ground damage incidents to aircraft, Wenner and Drury (1996) found similar error-affording factors : poor equipment and not using the correct number of personnel to carry out the job.

In a recent review of 1991-1995 marine accidents in Australian waters, the Marine Incident Investigation Unit (1996) identified recurring causal patterns for both groundings and collisions - the two most common accident types, accounting for $60 \%$ of all incidents. Of the groundings, $76 \%$ occurred either in the inner route of the Great Barrier Reef(Torres Straits) or close to, or within, port limits. Of the incidents, $33 \%$ involved ships where the pilot was on the bridge directing navigation (that is, pilot-assisted accidents). On those occasions when a pilot was not aboard, 36\% occurred between midnight and 04:00 hours. Among the collisions, $83 \%$ were between large trading vessels and small fishing boats or yachts. The collisions were facilitated by the failure to keep a proper lookout by all the vessels concerned and, in many cases, a lack of knowledge of the International Collision Regulations by those operating the smaller vessels.

In every recurrent accident scenario, there would seem to be at least three elements:

(1) Universals. These are the ever-present hazards associated with a particular domain of activity. In the maritime world, for example, these would include rocks, shallows, currents and tides, and the presence of other vessels. In aviation they comprise 
gravity, weather and terrain. It is unplanned contacts with these universals that do the actual damage.

(2) Local traps. These are characteristics of the task or workplace that, in combination with human error and violation tendencies lure people into repeated patterns of unsafe acts or less-than-adequate performance. Such snares are likely to be fairly enduring features of a particular work situation. They are analogous to the snakes on the snakes-and-ladders board. If we land on a square with a snake's head then we are inexorably pulled down to the snake's tail. Translating this into the real world, each 'snake' in a hazardous workplace has a region of attraction around its head and the power to elicit a sequence of unwise acts along its body, while its tail leads into an area of unacceptable danger. The crucial feature of these 'snakes' is that they have the power to lure people into a series of unsafe acts. irrespective of who they are. Clearly, it is possible to resist these traps, but they nonetheless have a particular and persistent ability to lead people into danger.

(3) Drivers. No psychologist was more concerned than Sigmund Freud with the motive forces that drive people into erroneous behaviour. In discussing the mechanisms underlying slips of the tongue, he made the following very pertinent observations: 'The influence of sound-values, resemblances between words, and common associations connecting certain words, must also be recognized as important. They facilitate the slip by pointing out a path for it to take. But if there is a path before me does it necessarily follow that I must go along it? I also require a motive determining my choice and, further, some force to propel me forward' (Freud 1922: 36).

A similar argument can be applied to the local traps in hazardous operations. Their mere existence is insufficient to explain why people are repeatedly-but not invariably-ensnared by them. They are the necessary but insufficient causes of recurrent accidents. The sufficiency is supplied by something that drives people towards and then along these treacherous pathways. The argument to be offered here is that, in hazardous work, this motive force is derived from an organization's safety culture - or, more specifically, from an unsafe culture.

It is clear from in-depth accident analyses that some of the most powerful pushes towards local traps come from an unsatisfactory resolution of the inevitable conflict that exists (at least in the short-term) between the goals of safety and production. The cultural accommodation between the pursuit of these goals must achieve a delicate balance. On the one hand, we have to face the fact that no organization is just in the business of being safe. Every company must obey both the 'ALARP' principle (keep the risks as low as reasonably practicable) and the 'ASSIB' principle (and still stay in business). On the other hand, it is now increasingly clear that few organizations can survixe a catastrophic organizational accident (Reason 1997). But there are also a number of more subtle economic factors at work.

As Hudson (1996) has pointed out, there can be a close relationship between the amount of risk taken and profitability. In hazardous work, as in exercise regimes, there is little gain without pain - or at least the increased likelihood of it. In oil exploration and production, for example, Hudson identified three levels of risk:

(1) Very low risk where the return on investment may be only $8 \%$ or lower-hardly more than would be expected from keeping the money in a bank.

(2) Moderate or manageable risk where the return might be $12 \%$.

(3) High risk where the return may increase to $15 \%$, but the margins between this and wholly unacceptable risks might be very small indeed. 
To remain competitive, many companies must operate mainly in the moderate risk zone with occasional excursions into the high risk region. As the distance to the 'edge' diminishes so the number of local traps increases. Here, the 'snakes' are likely to be more numerous and need only be quite short to carry the system over the edge, while the cultural drivers (pressures to get the job done no matter how) are likely to be exceedingly powerful indeed.

In summary, the same cultural drivers-time pressure, cost-cutting, indifference to hazards and the blinkered pursuit of commercial advantage - act to propel different people down the same error-provoking pathways to suffer the same kinds of accidents. Each organization gets the repeated accidents it deserves. Unless these drivers are changed and the local traps removed, the same accidents will continue to happen. The next section discusses how these cultural improvements might be achieved.

\section{Can a safe culture be socially engineered?}

It was proposed earlier that, for all practical purposes, a safe culture could be equated to an informed culture. That is, one in which the members of the organization understand and respect the hazards facing their operations, and are alert to the many ways in which the system's defences can be breached or bypassed. In short, an informed culture is one in which people, at all levels, do not forget to be afraid. They know where the 'edge' is without having to fall over it.

In many hazardous operations, and particularly in complex, well-defended ones, the accident rate has fallen to a low, asymptotic level at which there are too few negative outcomes to guide effective safety management. In commercial aviation, for example, the fatal accident rate has remained steady at around one per million departures for the past 25 years - despite the very considerable technological changes that have taken place in this period. In certain North Sea oil and gas installations, the lost time injury rate for 45-50year-old workers is less than that in mainland Scotland. With rates such as these, annual or biannual fluctuations are more likely to contain noise rather than valid indications of system safety.

In the absence of sufficient accidents to steer by, the only way to sustain a state of intelligent and respectful wariness is by creating a safety information system that collects, analyses and disseminates the knowledge gained from incidents, near misses and other 'free lessons'. To achieve this, it is first necessary to engineer a reporting culture not an easy thing, especially when it requires people to confess their own slips, lapses and mistakes.

O'Leary and Chappell (1997), the architects of two very successful aviation reporting systems (NASA's Aviation Safety Reporting System and the British Airways Safety Information System), have recently described the features that serve to persuade people to report near misses and incidents. All are within the scope of social engineering. They include confidentiality or the de-identification of reporters; the separation of the agency or department collecting and analysing the reports from those bodies with authority to institute disciplinary proceedings and impose sanctions; rapid, useful, accessible and intelligible feedback to the reporting community; and making it easy for reporters to complete and file reports. All of these are necessary to ensure a widely used reporting system, but the single most important factor is trust. And, to achieve this among potential reporters, we must first engineer a just culture.

An effective reporting system depends, crucially, upon how an organization handles blame and punishment. This lies at the heart of any safety culture. In reaction to the more 
punitive cultures of earlier times, it has become fashionable to talk of a 'no blame' culture, implying a blanket amnesty on all types of unsafe behaviour. But this is neither feasible nor desirable. A small proportion of unsafe acts-particularly reckless non-compliance and substance abuse - are truly egregious and deserve severe sanctions. A culture in which all acts are immune from punishment would lack credibility in the eyes of the workforce. In most organizations, the people at the sharp end know who the habitual rule-benders are, and it is they who are most likely to be endangered by their reckless behaviour. Seeing them getting away with these actions on a daily basis does little for morale or for the credibility of the management. Removing such habitual offenders makes the work environment a safer place. It also means that the organizational culture is more likely to be perceived as a just one.

A prerequisite for a just culture is that all members of an organization should understand where the line must be drawn between unacceptable behaviour, deserving of disciplinary action, and the remainder, where punishment is neither appropriate nor helpful in furthering the cause of safety. This is no easy task and continues to challenge the criminal justice systems of the civilized world.

Consider, for example, the distinction between errors and violations (Reason 1990). Nearly all errors are unintended, while most violations involve a conscious decision to depart from standard operating procedures. Should all unwitting errors be exempt from disciplinary action (in accordance with the legal doctrine of mens rea) and all deliberate violations be punished? Unfortunately, it is not as simple as that. Marx (1997a, b), a safety consultant with both aviation engineering and legal qualifications, has devoted considerable expert attention to the question of where the disciplinary line must be drawn. In regard to errors, he argues that neither the error nor the magnitude of its consequences should be the focus of the subsequent investigation. Rather, it is the individual's underlying conduct at the time the error was committed that is the proper subject of the review. The error may be unintended, but the course of action in which it occurred was not. He described two scenarios to make this distinction clearer.

In the first, a technician is assigned to inspect for cracks in an aircraft's fuselage. It is night and the aircraft is parked on the tarmac. In accordance with the airline's policy, the technician wheels out a work stand to bring him close to the skin and obtains bright lights to illuminate the work. Despite these measures, it is later found that a crack in the fuselage was not discovered, seriously endangering the aircraft and its occupants. The second scenario has the same outcome: a crack is missed. But, this time, the technician conducted his inspection by merely walking beneath the aircraft using a hand-held flashlight to illuminate the rivets, some 2 metres away.

In neither case was the error intended. But, in the latter case, there is little doubt that the cursory and distant examination greatly increased the probability of a fuselage crack being missed. The first technician, on the other hand, was a xictim of circumstance. He did not wittingly decrease the inherent reliability of this task. The second person, however, deliberately engaged in a form of behaviour that significantly and unjustifiably increased the risk of an error occurring.

It could be suggested that the difference between the two technicians was simply that one complied with company procedures in carrying out his inspection, while the second did not. Thus, it might be argued that the issue of culpability turns solely on whether an individual was violating at the time an error was made. But that, too, proves not to be so simple if we consider a third scenario.

The basic situation is the same as before. But, this time, the technician discovers that the appropriate work stand is broken and there are no strong lights available. The shift is short 
handed and the aircraft is due to depart very shortly. He believes he has only two options: either to abandon the fuselage inspection because he does not have the required equipment, or to carry out a walk-under inspection using a flashlight. He decides upon the latter course and, as before, a dangerous crack is missed.

The nature of violations has been considered at length elsewhere (Reason 1990, 1997, Free 1994, Reason et al. 1994, Hudson et al. 1997). For our present purposes, it is sufficient to note that they come in different forms and two, in particular, are of relevance here: routine and necessary violations. Violations have both motivational and situational origins and understanding the balance between them is essential for establishing culpability in a just manner.

Routine, or corner-cutting, violations typically involve taking the path of least effort between two task-related points, regardless of what the procedures may direct. On the face of it, these seem to be due to laziness and hence blameworthy. But, even here, the issues are not clear-cut. Procedures may not always stipulate the most efficient way of doing a job, and so they might be 'rewritten on the hoof' by skilled workers who discover both a safe and a less labour-intensive means of doing a job. A survey of human performance problems in the nuclear power industry established that some $60 \%$ of these errors could be traced to inadequate or unworkable operating procedures (INPO 1985).

Necessary violations, on the other hand, arise largely from inadequacies of the equipment or workplace that make it impossible to carry out the work and still comply with the procedures. However unwise they may turn out to be, the motives for committing necessary violations have nothing to do with cutting corners or thrill-seeking. Their goal is simply to get the job done despite the local difficulties. As such, the responsibility for their occurrence lies more with the organization at large than with the individuals concerned.

The violation described in the second scenario falls clearly into the routine or cornercutting category. Here, the technician's main motive was to minimize effort. In the third scenario, however, the technician's primary concern was to carry out a safety inspection, despite the local equipment deficiencies. Better to carry out a cursory inspection than none at all, he might have reasoned. Even though he deliberately violated company procedures and made an error in the process, he was still a xictim of circumstances for which the company was ultimately responsible.

In a more recent publication, Marx (1997b) argued that organizations should not focus upon rule violations in the disciplinary decision process. The task of these decision makers should be to evaluate the erring technician's conduct in the light of what was reasonable to do in the circumstances. The behaviour should be judged not upon the existence of rule violations, but upon the presence or absence of intentional (hence reckless) risk-taking. He gives the following example:

'Consider the technician who, in towing an aircraft around a crowded gate area at Chicago O'Hare, decides not to use wing walkers. In doing so, he hits another aircraft with his aircraft's wing tip. Does the determination of whether the technician was reckless really hinge upon the presence of a rule requiring wing walkers. Or is his behaviour inherently reckless, with or without the presence of a rule?' (Marx 1997b: 4).

These are very fine judgements. So what is the best way to achieve a just distinction between blameless and blameworthy actions? Johnston (1995), a human factors specialist and an Aer Lingus training captain, has proposed the substitution test. When faced with an event in which the unsafe acts of a particular individual were clearly implicated, the judges should carry out the following thorough experiment. Substitute for the person concerned someone coming from the same work area and possessing comparable qualifications and experience. Then ask: 'In the light of how the events unfolded and were perceived by those 
involved in real time, is it likely that this new individual would have behaved any differently?' If the answer is 'probably not' then, as Johnston (1996: 34) put it, 'apportioning blame has no material role to play, other than to obscure systemic deficiencies and to blame one of the victims'.

A useful variant on the substitution test is to ask of the individual's peers: 'Given the circumstances that prevailed at the time, could you be sure that you would not have committed the same or a similar type of unsafe act?' If the answer again is 'probably not', then blame and punishment are inappropriate. Whatever the mechanism, however, it is important that peers as well as managers should be involved in the disciplinary judgement process (Marx 1997b).

What could we hope to achieve from such fine distinctions? There are at least two beneficial outcomes. First, a culture in which each individual is clear about what determines the difference between acceptable and unacceptable actions. Second, a culture in which the vast majority of errant behaviours could be reported without fear of punishment. In short, we would have achieved the prerequisite for a reporting culture. This, in turn, would form the main foundation of an informed culture.

\section{Conclusions}

If there has been a single thread running through these various arguments, it concerns the need for an organization to inculcate and then sustain a healthy but intelligent respect for the hazards that threaten its operations. This is not easy to achieve. Several powerful factors act to push safety into the background of an organization's collective awareness, particularly if it possesses many elaborate barriers and safeguards. But it is just these defences-in-depth that render such systems especially vulnerable to adverse cultural influences. Organizations are also prey to external forces that make them either forget to be afraid, or even worse, avoid fear altogether. The penalties of such complacency can be seen in the recurrent accident patterns in which the same cultural drivers, along with the same uncorrected local traps, cause the same bad events to happen again and again.

It need not be necessary to suffer a corporate near-death experience before acknowledging the threat of operational dangers - though that does appear to have been the norm in the past. If we understand what comprises an informed culture, we can socially engineer its development. Achieving a safe culture does not have to be akin to a religious conversion-as it is sometimes represented. There is nothing mystical about it. It can be acquired through the day-to-day application of practical down-to-earth measures. Nor is safety culture a single entity. It is made up of a number of interacting elements, or ways of doing, thinking and managing, that have enhanced resistance to operational dangers as their natural by-product.

\section{References}

BASI 1995, Israel Aircraft Industries Westwind 1124 VH-AJS Alice Springs Northern Territory, 27 April 1995. Investigation Report No. 9501246 (Canberra: Bureau of Air Safety Investigation).

BATE, P. 1992, The impact of organisational culture on approaches to organisational problemsolving. In G. Salaman (ed.), Human Resource Strategies (London: Sage).

$F_{A Y}$, S. 1996, The Collapse of Barings (London: Arrow Business).

FREE, R. 1994, The role of procedural violations in railway accidents. $\mathrm{PhD}$ thesis, University of Manchester.

FReUd, S. 1922, Introductory Lectures on Psychoanalysis (London: George Allen). 
Hobss, A. 1997, Human Factors in Airline Maintenance: A Study of Incident Reports (Canberra: Bureau of Air Safety Investigation).

Hofstede, G. 1994, Cultures and Organisational: Intercultural Co-operation and its Importance for Survival (London: Harper Collins).

Hudson, P. T. W. 1996, Psychology and Safety. Unpublished report (Leiden: Rijks Universiteit Leiden).

Hudson, P. T. W., Verschuur, W. L. G., Lawton, R., Parker, D. and Reason, J. 1997, Bending the Rules II: The Violation Manual (Leiden: Rijks Universiteit Leiden).

INPO 1984, An Analysis of Root Causes in 1983 Significant Event Reports. INPO 84-027 (Atlanta: Institute of Nuclear Power Operations).

INPO 1985, An Analysis of Root Causes in 1983 and 1984 Significant Event Reports. INPO 85-027 (Atlanta: Institute of Nuclear Power Operations).

JoHnston, N. 1995, Do blame and punishment have a role in organisational risk management? Flight Deck, 15, 33-36.

Legasov, V. 1988, The Legasov Tapes (Washington: Department of Energy, translated from Pravda).

MARx, D. 1997a, Discipline: the importance of mens rea, Ground Effects, 2, 1-5.

MARX, D. 1997b, Discipline: the role of rule violations, Ground Effects, 2, 1-4.

Massie, R. K. 1992, Dreadnought: Britain, Germany, and the Coming of the Great War (London: Jonathan Cape).

Medvedev, G. 1991, The Truth about Chernobyl (New York: Basic).

MIIU 1996, Marine Incident Investigation Unit 1991-1995 (Canberra: Department of Transport and Regional Development).

NTSB 1994, Controlled Flight into Terrain Federal Aviation Administration Beech Super King Air 300/F, N82, Front Royal, Virginia, October 28, 1993. NTSB/AAR-94/03 (Washington: National Transportation Safety Board).

NTSB 1996, Collision of Washington Metropolitan Area Transit Authority Train T-111 with Standing Train at Shady Grove Passenger Station, Gaithersburg, Maryland. January 6, 1996. NTSB/RAR96/04 (Washington: National Transportation Safety Board).

NTSB 1997, Wheels-up Landing Continental Airlines Flight 1943 Douglas DC-9 N10556, Houston, Texas, February 19, 1996. NTSB/AAR-97/01 (Washington: National Transportation Safety Board).

Q'LEARY, $M$. and CHAPPELL, S. L. 1997. Confidential incident reporting systems create vital awareness of safety problems, ICAO Journal, 51, 11-13.

Perin, C. 1992, British Rail: the case of the unrocked boat. In Workshop on Managing the Technological Risk in Industrial Society, 14-16 May, Bad Homburg, Germany.

Perrow, C. 1984, Normal Accidents: Living with High-Risk Technologies (New York: Basic).

RASMUSSEN, J. 1993, Learning from experience? Some research issues in industrial risk management. In B. Wilpert and T. Qvale (eds), Reliability and Safety in Hazardous Work Systems (Hove: LEA).

Reason, J. 1990, Human Error (New York: Cambridge University Press).

Reason, J. 1995, Comprehensive Error Management in Aircraft Engineering: A Manager's Guide (London Heathrow: British Airways Engineering).

Reason, J. 1997, Managing the Risks of Organizational Accidents (Aldershot: Ashgate).

REASON, J PARKER, D and FREE, R. 1994. Bending the Rules: The Varieties, Origins and Management of Safety Violations (Leiden: Rijks Universiteit Leiden).

Schein, E. H. 1985, Organizational Culture and Leadership (San Francisco: Jossey-Bass).

Thompson, N., Stradiing, S., Murphy, M. and O'Neill, P., 1996, Stress and organisational culture, British Journal of Social Work, 26, 647-665.

UtTAL, B. 1983, The corporate culture vultures. Fortune Magazine, 17 October.

WeICK, K. E. 1991, Organizational culture as a source of high reliability, California Management Review, 29, 112-127.

WenNER, C. and Drury, C. G. 1996, Active and latent failures in aircraft ground damage incidents. Proceedings of the Human Factors and Ergonomics Society 40 th Annual Meeting (San Diego: Human Factors and Ergonomics Society), pp. 796-801.

WeStRum, R. 1996, Safety of a technological system. NTSB Symposium on Corporate Culture and Transportation Safety, 24-25 April, Crystal City, Virginia. 